\title{
Study on The Effect of Different Plenum Chamber Coefficients on Frosting of Air-cooler
}

\author{
Bin Liu ${ }^{1, *}$, Shengqiang Shi ${ }^{1}$, Yongshan Liu ${ }^{1}$, Rachid Bennacer ${ }^{2}$, Aiqiang Chen ${ }^{1}$, and Panagiotis E. Theodorakis ${ }^{3}$ \\ ${ }^{1}$ Tianjin University of Commerce, Tianjin Key Laboratory of Refrigeration Technology, Tianjin, 300134, P. R. China \\ ${ }^{2}$ LMT/ENS-Cachan/CNRS, Paris-Saclay University, 61 Avenue Du Président Wilson, 94235, Cachan, France \\ ${ }^{3}$ Institute of Physics, Polish Academy of Sciences, Al. Lotników 32/46, 02-668 Warsaw, Poland
}

\begin{abstract}
The performance of the air-cooler in the refrigeration system plays a key role in improving the energy efficiency. Here, the plenum chamber coefficient was defined to study a possible way of enhancing the refrigeration system performance. In order to investigate the influence of the plenum chamber coefficient on the frosting and the cooling system of the chillers, three plenum chamber coefficients $(0.74,0.97,1.2)$ were studied under high humidity. The temperature decreasing curve of the environmental chamber, the velocity distribution of the air cooler, and the frost accumulation under and on the air-cooler were analysed. The results show that the frost accumulation on the tube will increase with the increase of the plenum chamber coefficient and the frost accumulation on the fin will increase at first and then decrease with the increase of the plenum chamber coefficient. On the whole, in this study, frosting is the most obvious when the plenum chamber coefficient was 0.97 .
\end{abstract}

\section{Introduction}

The performance of the air-cooler in the refrigeration system plays a key role in improving the energy efficiency. During the operation process of the air cooler, frosting is one of the main reasons restricting its operation efficiency [1]. Since the thermal conductivity of the frost layer itself is only $0.116-0.139 \mathrm{~W} /(\mathrm{m} \cdot \mathrm{K})$, and its thermal resistance is $94-443$ times that of aluminium and copper metals, the formed frost layer will affect the heat transfer of the fins and the evaporation tube, thereby reducing the efficiency of the air-cooler [2]. The continuous accumulation of frost on the air-cooler of the system for a long time will block the air passage and increase the flow resistance, which will in turn seriously affect the convective heat transfer coefficient, reduce the heat exchange efficiency of the air-cooler and the COP of the entire system [3-6]. Therefore, the investigation of the frost formation process is important for air-cooler operation.

Frosting is a water vapor condensation and freezing process or direct desublimation of water on cold surfaces exposed in humid environment $[7,8]$. There are many factors, such as air velocity $[9,10]$, air temperature $[11,12]$, humidity [13], cold wall temperature [14] and the shape of cold surface $[15,16]$ that influence surface frosting [17]. Therefore, during the past several decades, there has been a continuing effort to advance the understanding and modelling of frost formation on cold surfaces based on experimental, semi-empirical, theoretical, and numerical approaches. Kim et al. [18] presented a CFD-based model to predict macroscopic and local frost behaviours on a cold plate, which could describe frost growth details. Wu et al. [19] proposed a phase change mass transfer model to predict frost growth and densification. Their results have indicated that frost was first formed around the cooling block and then was extended gradually to other directions. Also, they have found that the growth rate of the average frost thickness decreased over time. Negrelli et al. [20] simulated the frost growth by using fractal theory. They determined the density based on the mass conservation principle and calculated the effective thermal conductivity by using the finite-volume method. Brèque and Nemer [21] presented equations for frost models and the main different hypotheses and compared the different hypotheses with experimental data. Benítez and Sherif [22] used the orthogonal collocation method to solve the equations that describe the frost formation process when a cold flat plate is exposed to a humid air stream. The model results were found to agree closely with available experimental data. Sommers et al. [23] proposed a new semi-empirical correlation, which was a function of the modified Jakob number and contained two correction terms. Zendehboudi et al. [24] used 711 organized data samples to train and test the model, and conducted comprehensive error analysis to verify the adaptive neuro-fuzzy reasoning system.

At present, modelling and dimensionless analysis are mostly used to study the frosting amount of a single fin of an air cooler [25]. Jung-Soo Kim [26] proposed formula 1 for the range of Reynolds numbers $700-3000$ (the corresponding experimental speed is $0.5 \mathrm{~m} / \mathrm{s}-$ $2 \mathrm{~m} / \mathrm{s}$ ), Fourier numbers $56.8-295.7$ (the corresponding experimental time is $0-100 \mathrm{~min}$ ), moisture content $0.00028-0.00568$, air temperature $3-9^{\circ} \mathrm{C}$, and cold

\footnotetext{
*Corresponding author: lbtjcu@ticu.edu.cn
} 
surface temperature $-32^{\circ} \mathrm{C}--20^{\circ} \mathrm{C}$, which can lead to an error between theory and experiment within $15 \%$.

$$
\begin{gathered}
y_{f r}^{*}=3.236\left(\operatorname{Re}_{L, f i n}\right)^{4.447 \times 10^{-2}}\left(F_{O_{L}}\right)^{0.550}\left(w_{a}\right)^{1.267}\left(T_{a}^{*}\right)^{-14.884}\left(T_{W}^{*}\right)^{-8.400}(1) \\
T_{a}^{*}=\frac{T_{a}}{T_{t p}} ; T_{W}^{*}=\frac{T_{W}}{T_{t p}}
\end{gathered}
$$

Lee et al. [27] have performed research on heat exchangers with variable fin spacing of $5-15 \mathrm{~mm}$. They have suggested formula 3 for frost thickness when fin spacing is $5-15 \mathrm{~mm}$, Fourier number is $0-550$, Reynolds number is $100-1350$, air temperature is $3-$ $15^{\circ} \mathrm{C}$, relative humidity is $70-90 \%$, and cold surface temperature is $-30--20^{\circ} \mathrm{C}$. The deviation from experimental data is within $10 \%$.

$y_{f r}=9.1251 \times \operatorname{Re}_{D h}^{0.2011} \times\left(F O_{L}\right)^{0.3941} \times\left(T^{*}\right)^{1.2031} \times w_{a}^{1.1121}$

(3)

Although these models and dimensionless formulas are consistent with the experimental data of heat transfer and mass transfer in the process of frosting, these empirical formulas and models still have certain limitations and applicability. In systems such as cold storage, there are few appropriate associations in the existing literature that match experimental phenomena. In order to fill the study gaps, this article first defines a coefficient: the plenum chamber coefficient $\Phi$, that is, the ratio of the distance between the fan and the fin and the diameter of the air outlet. Since the diameter of the air outlet of the selected air cooler is fixed, the distance between the fan and the fin is adjusted to obtain different plenum chamber coefficients. Secondly, by changing the initial relative humidity, measuring the growth of the frost layer of the evaporator tube and the fin, so as to explore the influence of different plenum chamber coefficients on the frosting of the air-cooler law. Finally, according to the experimental conditions and the measured value of frosting, the dimensionless analysis method is used to derive the relative formulas of the frosting layer between the fin and the evaporator tube in the air-cooler respectively, which can provide a reference for the system design and operation in future.

\section{Experimental setup}

\subsection{Experimental facility}

Fig.1 shows a schematic diagram of the experimental setup. The experimental setup consists of a test section and a chiller unit for controlling the temperature. The test section includes an air cooler whose fins and evaporator tubes frosting as the experiment progresses; the humidifier to change air humidity; measuring device to detect frost thickness, cold storage temperature and humidity in a timely manner.

The refrigerant used in these experiments was R404A. The compressor adopts TFH2480Z compressor from Tecumseh, France. The conventional tube-fin condenser is selected as the experimental object. The outer size of the condenser is $440 \mathrm{~mm}$ in depth, $90 \mathrm{~mm}$ in width, and $400 \mathrm{~mm}$ in height. The heat exchange area of the condenser is about $5.98 \mathrm{~m}^{2}$, including 64 condenser tubes and 145 fins. The rows of condenser tubes are arranged crosswise, with a spacing of $26 \mathrm{~mm}$. Besides, the fins are sleeve type and the spacing of fins is $3 \mathrm{~mm}$. The model of supporting condensing fan is YS10$3530 \mathrm{~A}-4 \mathrm{~T}-4390$, with rated power of $120 \mathrm{~W}$ and rated speed of $1420 \mathrm{r} / \mathrm{min}$. The size of the reservoir is $280 \mathrm{~mm}$ in height and $130 \mathrm{~mm}$ in diameter and the drying filter adopts EK-053.

The type of expansion valve is very important for the frosting test because this apparatus significantly affects the characteristic of the frosting test [28]. Therefore, the expansion valve adopts TES02 produced by Danvers. The condensation temperature of the expansion valve is $30^{\circ} \mathrm{C}$, the supercooling temperature is $2^{\circ} \mathrm{C}$, and the evaporation temperature is $10^{\circ} \mathrm{C}$. The rated cooling capacity of the expansion valve at $0^{\circ} \mathrm{C}$ overheating is $1.204 \mathrm{KW}$, the front and rear pressure drop is $0.9985 \mathrm{MPa}$, and the flow rate is $1.62 \mathrm{~m} / \mathrm{s}$.

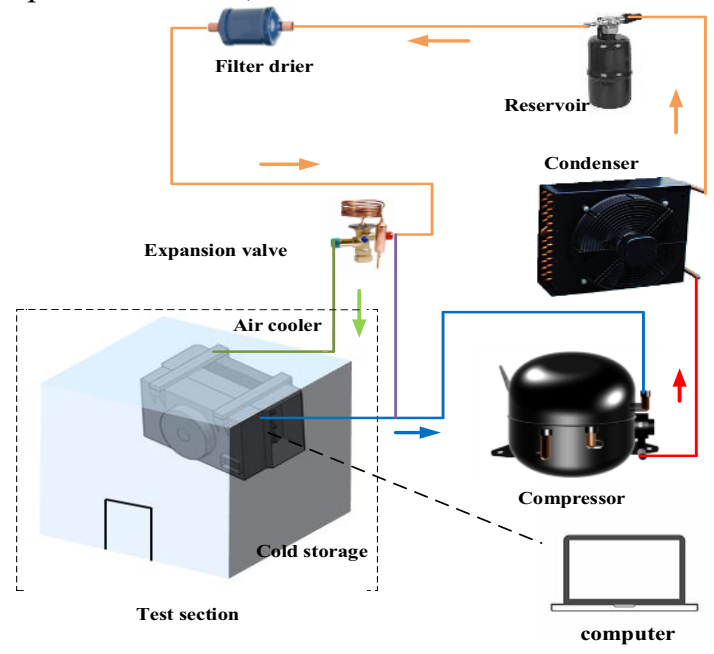

Fig. 1. Schematic diagram of the experimental setup.

Fig. 2 is the structure diagram of the air-cooler. The outer size of the air-cooler is $520 \mathrm{~mm}$ in depth, $140 \mathrm{~mm}$ in width, and $500 \mathrm{~mm}$ in height. The total area of heat exchange on the outer surface of the air-cooler is $6.52 \mathrm{~m}^{2}$, including 56 evaporation tubes and 51 fins. Evaporation tubes are interlaced, divided into 4 rows, each row of 14 . The tube spacing is $40 \mathrm{~mm}$ and the fin spacing is $10 \mathrm{~mm}$. The supporting fan is YSWF74L34P4-350SLF, with rated power of $150 \mathrm{~W}$, rated speed of $1400 \mathrm{r} / \mathrm{min}$ and air volume of $3110 \mathrm{~m}^{3} / \mathrm{h}$. The difference with the conventional air cooler is that through customization, the air outlet side is added with a plenum chamber. The upper side of the plenum chamber is linked with a hinge device, so that the distance between the fan and the fin air outlet surface can be adjusted. 


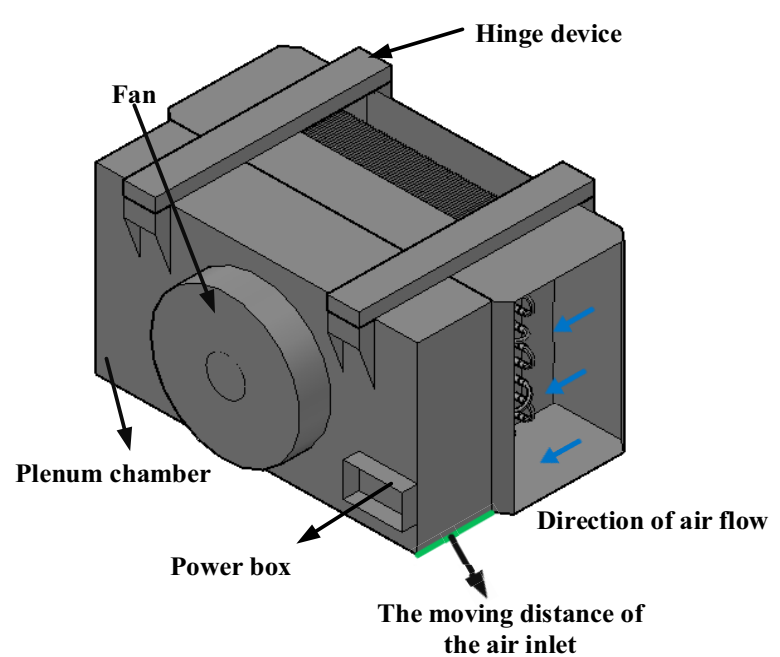

Fig. 2. Concrete structure diagram of the air cooler.

\subsection{Measuring device and monitoring point arrangement}

Table 1 shows the measuring instruments used in the experiment, the measuring range, and the accuracy of the instruments.

Table 1. Specifications of the measuring devices.

\begin{tabular}{|c|c|c|c|c|}
\hline $\begin{array}{c}\text { Paramet } \\
\text { er }\end{array}$ & Devices & Type & Range & Accuracy \\
\hline $\begin{array}{l}\text { Ambient } \\
\text { /water } \\
\text { temperat } \\
\text { ure }\end{array}$ & $\begin{array}{c}\text { Thermocou } \\
\text { ple }\end{array}$ & $\begin{array}{l}\text { T-type } \\
\text { Thermo } \\
\text { couple }\end{array}$ & $\begin{array}{c}-200^{\circ} \mathrm{C} \\
\text { to } \\
350^{\circ} \mathrm{C}\end{array}$ & $\pm 0.75 \%$ \\
\hline Pressure & $\begin{array}{l}\text { Pressure } \\
\text { Sensor }\end{array}$ & $\begin{array}{c}\text { EET- } \\
100\end{array}$ & $\begin{array}{c}0 \mathrm{MPa} \\
\text { to } \\
12 \mathrm{MPa}\end{array}$ & $\pm 0.5 \% \mathrm{FS}$ \\
\hline $\begin{array}{l}\text { Temper } \\
\text { ature } \\
\text { and } \\
\text { pressure } \\
\text { data } \\
\text { collectio } \\
\text { n }\end{array}$ & $\begin{array}{l}\text { Real-time } \\
\text { data } \\
\text { acquisition } \\
\text { system }\end{array}$ & MX-100 & - & - \\
\hline $\begin{array}{c}\text { Humidit } \\
\mathrm{y}\end{array}$ & Humidifier & SJ-01 & $\begin{array}{c}-5^{\circ} \mathrm{C} \text { to } \\
40^{\circ} \mathrm{C}\end{array}$ & - \\
\hline $\begin{array}{l}\text { Humidit } \\
\text { y data } \\
\text { collectio } \\
\text { n }\end{array}$ & Hygrometer & $\begin{array}{c}\text { CF5020 } \\
\mathrm{Y}\end{array}$ & $\begin{array}{c}0 \mathrm{RH} \text { to } \\
100 \% \mathrm{R} \\
\mathrm{H}\end{array}$ & $\pm 2 \%$ \\
\hline Air flow & $\begin{array}{c}\text { Anemomete } \\
\mathrm{r}\end{array}$ & $\begin{array}{c}6243 \\
\text { Multipoi } \\
n t \\
\text { Anemo } \\
\text { meter }\end{array}$ & $\begin{array}{l}0 \mathrm{~m} / \mathrm{s} \text { to } \\
9.9 \mathrm{~m} / \mathrm{s}\end{array}$ & $\pm 0.01 \mathrm{~m} / \mathrm{s}$ \\
\hline $\begin{array}{c}\text { Compre } \\
\text { ssor } \\
\text { power }\end{array}$ & Power meter & $\begin{array}{c}\text { WT310 } \\
\text { E power } \\
\text { meter }\end{array}$ & $\begin{array}{l}0 \mathrm{~V} \text { to } \\
600 \mathrm{~V}\end{array}$ & \\
\hline
\end{tabular}

\subsection{Test section}

In the test part, five cameras are used to take photos of the fin and the evaporator for observation of the frost thickness at regular intervals, the specific layout points are shown in Fig.3.
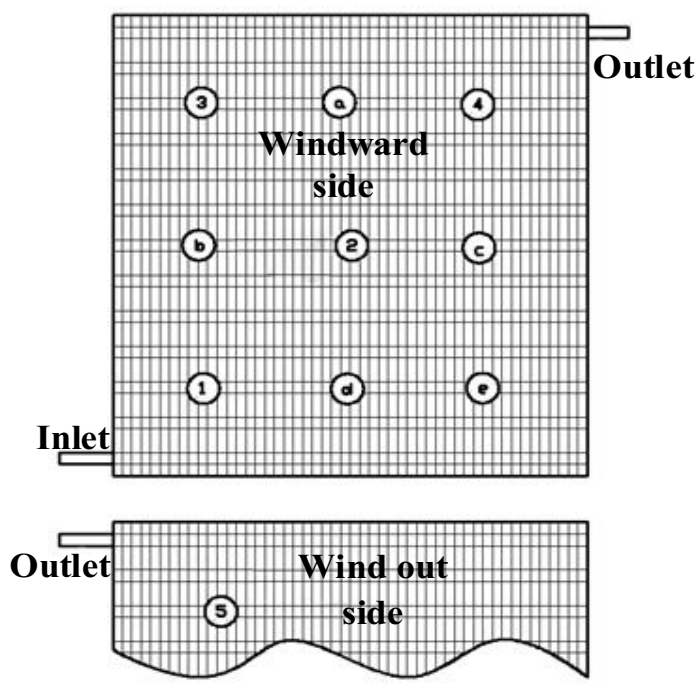

Fig. 3. Measuring point position of frost layer on evaporator.

\section{Results and analysis}

Combined with Fig. 4 (a), Fig. 4 (b) and Fig. 4 (c), it is found that when the coefficient of the plenumb chamber is $0.74,0.97$ and 1.2 respectively, for the first four measuring points, the growth rate of ice on the evaporation tube in $0-2 \mathrm{~h}$ is significantly faster than that in the following moments. In the first two hours, the growth rates of the four measuring points are $0.27 \mathrm{~mm} / \mathrm{h}$ $-0.41 \mathrm{~mm} / \mathrm{h}, 0.24 \mathrm{~mm} / \mathrm{h}-0.28 \mathrm{~mm} / \mathrm{h}$, and $0.23 \mathrm{~mm} / \mathrm{h}-$ $0.28 \mathrm{~mm} / \mathrm{h}$, respectively. However, the growth rates in the next 16 hours are an order of magnitude lower than those in the first two hours, which are $0.0044 \mathrm{~mm} / \mathrm{h}-$ $0.011 \mathrm{~mm} / \mathrm{h}, 0.023 \mathrm{~mm} / \mathrm{h}-0.044 \mathrm{~mm} / \mathrm{h}, 0.014 \mathrm{~mm} / \mathrm{h}-$ $0.027 \mathrm{~mm} / \mathrm{h}$, respectively. Similarly, according to Fig. 4 (d), it is found that the frost layer growth rate of evaporator tubes and fins at the measuring point 5 within $0 \sim 2 \mathrm{~h}$ is still higher than that of the last 16 hours. This is due to the high temperature and high relative humidity in the initial cold storage, resulting in high moisture content in the air and rapid freezing and frosting. With the decrease of the temperature in the cold storage, although the relative humidity is still large, the moisture content is very limited, and the temperature difference between the wet air and the cold surface is gradually decreasing, resulting in a significantly slower rate of freezing and frosting.

At the same time, compared with the slow increase of ice at the first four measuring points after 2 hours, the frost layer growth of evaporator tubes and fins at the measuring point 5 still showed a linear growth. Furthermore, the frost layer growth rate on evaporator tubes is higher than that on fins at the same measuring point, and the frost thickness on evaporator tubes is greater than that on fins after $8.2 \mathrm{~h}$. 
Comparing the frost thickness of the previous three figures, Fig.4(d) show that the frost growth phenomenon at the measuring point 5 is more obvious. Moreover, since the first four measurement points are mainly iced, and the thermal conductivity of ice at $0^{\circ} \mathrm{C}$ is $2.24 \mathrm{~W} /$ $(\mathrm{m} \cdot \mathrm{K})$ far greater than the thermal conductivity of frost, so the main influence on the heat transfer of the aircooler lies in the frost layer on the outlet side. At the same time, it is obvious that the frost accumulation on the tube will increase with the increase of the plenum chamber coefficient and the frost accumulation on the fin will increase at first and then decrease with the increase of the plenum chamber coefficient. On the whole, in this study, frosting is the most obvious when the plenum chamber coefficient was 0.97 .

Since the temperature of the evaporator tube depends on the temperature after throttling and the

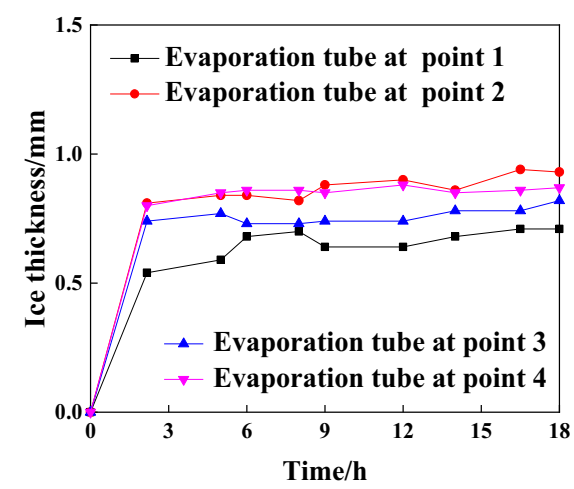

(a) $\Phi=0.74$

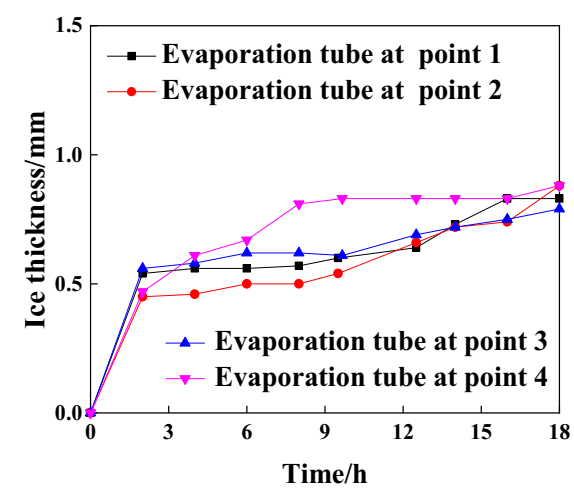

(c) $\Phi=1.2$ convection and thermal conductivity of the evaporator tube, the change of the plenum chamber coefficient will inevitably cause changes in the uniformity of the wind speed field, thus affecting the heat transfer performance of the local area and causing temperature differences.

The temperature of the evaporating tube is lower than the temperature of the fin. When the plenum chamber coefficient is 1.2 , the evaporating tube is more prone to frost than the fin as time increases. However, when the plenum chamber coefficient decreased to 0.74 and 0.97 , the wind speed is higher than a certain value, and more water vapor is carried to the measuring point 5. At this time, for the frosting, the heated area accounted for more factors, and compared with the evaporation tube area, the fin heated area is larger, so the thickness of the frost layer on the fin is higher than the thickness of the evaporation tube.

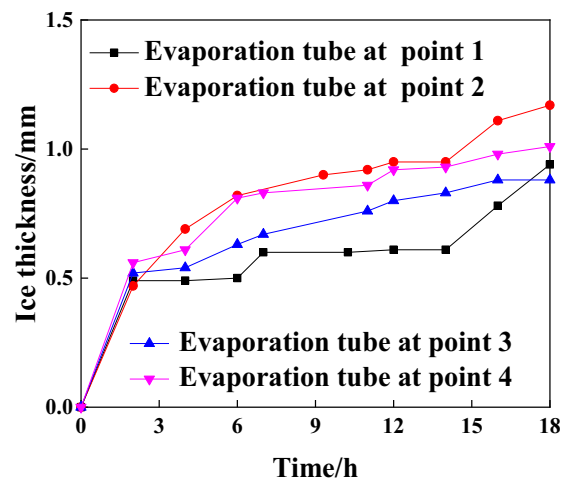

(b) $\Phi=0.97$

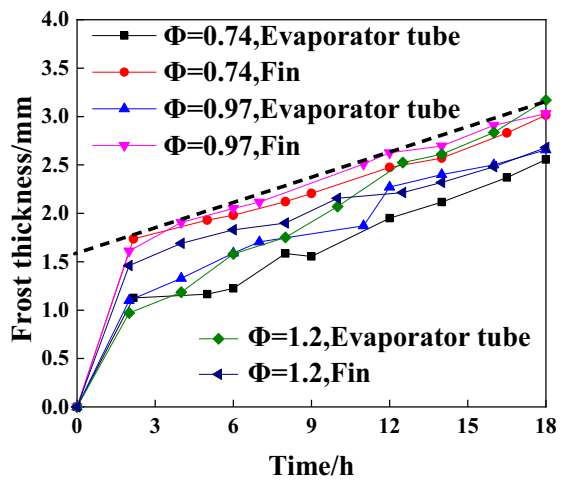

(d) Comparison of frost thickness at point 5 under different plenum chamber coefficients

Fig. 4. Ice or Frost curves of points to be measured under different plenum chamber coefficients.

\section{Derivation of dimensionless analytic fitting curves}

\subsection{Dimensionless relation for frosting on air- cooler fins}

For the fin, the frost layer within $0-2 \mathrm{~h}$ has its own special initial conditions, so according to the experimental results, only the part of $2-18 \mathrm{~h}$ will be analysed in the final verification and the formula refers to 4 and 5 :

$$
\begin{gathered}
M_{f r}=f\left(\rho_{f r, a v e}, y_{f r, a v e}\right) \\
M^{*}=f\left(T^{*}, w_{a}, \operatorname{Re}_{L, f i n}, F O_{L}, \xi_{f i n}^{*} \bullet \kappa_{f i n}^{*}\right) \\
T^{*}=\sqrt{\left(\frac{T_{a}-T_{t p}}{T_{a}-T_{W}}\right)^{2}} ; \operatorname{Re}_{L, f i n}=\frac{\left(u_{a} \cos \theta_{f i n}\right) L_{f i n}}{v} ; \xi_{f i n}^{*}=\frac{\xi_{f i n}}{\xi_{f i n, r}} \\
\kappa_{f i n}^{*}=\frac{\kappa_{f i n}}{\kappa_{f i n, r}}
\end{gathered}
$$

Where $\xi_{\text {fin }}$ is the thickness of the fin, $\xi_{f i n, r}$ is the reference value of the thickness of the fin, $\kappa_{f i n}$ is the 
thermal conductivity of the fin, and $\kappa_{f i n, r}$ is the thermal conductivity of the fin. The product of these four values can be viewed as a fixed value due to the same equipment and the same fin. There is a distance of about $110 \mathrm{~mm}$ from the passage through which the air enters the fin to the measuring point 5, and the distance between the fins is $10 \mathrm{~mm}$. Therefore, the fin and the air flow direction can consider to be the same, that is, $\cos \theta_{\text {fin }}=1$. Therefore, Formula 5 can be simplified into Formula 6:

$$
M^{*}=f\left(T^{*}, w_{a}, \operatorname{Re}_{L, f i n}, F O_{L}\right)
$$

Since the frost quality is related to the frost thickness and density, the densities of points with different numbers in the table are different. Formula 7 [29] can be used to calculate the density through the experimental wind speed and according to the density variation range of $155.9 \mathrm{~kg} / \mathrm{m}^{3} \sim 215.3 \mathrm{~kg} / \mathrm{m}^{3}$, formula 8 [30] is used for thermal conductivity.

$$
\begin{gathered}
\rho_{f r}=340\left|T_{W}\right|^{-0.445}+25 v_{\mathrm{a}} \\
\lambda_{f r}=1.202 \times 10^{-3} \rho_{f r}^{0.963}
\end{gathered}
$$

In addition, in the frost layer growth process, the density will also change. Therefore, we select the average density in the table state parameters in the calculation, that is, the average density is $190.2 \mathrm{~kg} / \mathrm{m}^{3}$ and the average thermal conductivity $\lambda$ is $0.188 \mathrm{~W} /(\mathrm{m} \cdot \mathrm{K})$. In the calculation of Reynolds number $\mathrm{Re}_{L, \text { fin }}$, according to the measured position, the length $L_{f i n}$ is $0.13 \mathrm{~m}$, the air density is $1.342 \mathrm{~kg} / \mathrm{m}^{3}$, the viscosity $v$ is $1.67 \times 10^{-5} \mathrm{~Pa} \cdot \mathrm{s}$. In the calculation of Fourier number $F_{O_{L}}$, the value of average thermal conductivity and average density is substituted, and the specific heat capacity $C$ is taken as $2100 \mathrm{~J} /(\mathrm{kg} \cdot \mathrm{K})$.

According to these conditions, the parameter values of each variable in different working conditions can be listed, as shown in Table 2 .

The dimensionless equation of frost layer growth is:

$$
M_{f i n}^{*}=m F O_{L}^{a} \cdot\left(T^{*}\right)^{b} \cdot \operatorname{Re}_{L, f i n}^{c} \cdot \omega^{d}
$$

Choose the appropriate values of $\mathrm{m}, \mathrm{a}, \mathrm{b}, \mathrm{c}$ and $\mathrm{d}$, and make the selected points and points on the curve as close to the curve as possible. Then, the fitting curves of the five groups of data are as follows:

$$
\begin{aligned}
& M_{\text {fin }}{ }^{*}= \\
& 1.333 \times 10^{-10} \mathrm{Fo}_{L}^{0.3764} \cdot\left(T^{*}\right)^{-0.1011} \cdot \mathrm{Re}_{L, \text { fin }}^{2.059} \cdot \omega^{-1.968}
\end{aligned}
$$

or

$$
\begin{aligned}
& M_{\text {fin }}{ }^{*}= \\
& 1.82 \times 10^{-7} \mathrm{FO}_{L}^{-2.345} \cdot\left(T^{*}\right)^{-10.1768} \cdot \mathrm{Re}_{L, f \text { in }}^{6.6566} \cdot \omega^{-39.5362}
\end{aligned}
$$

Table 2. Parameter values under different operating conditions.

\begin{tabular}{|c|c|c|c|c|c|}
\hline Item & $\boldsymbol{F O}_{L}$ & $\mathrm{~T}^{*}$ & $\mathrm{Re}_{L, \text { fin }}$ & $\begin{array}{c}\text { Moisture content } \omega \\
(\mathrm{g} / \mathrm{kg})\end{array}$ & $M^{*}$ \\
\hline 1 & 896.0396 & 1 & 25281.74 & 2.426 & 0.35 \\
\hline 2 & 3201.377 & 4.444444 & 17759.9 & 1.655 & 0.50 \\
\hline 3 & 1034.644 & 0.894737 & 24445.98 & 2.506 & 0.33 \\
\hline 4 & 1260.154 & 1.111111 & 22356.58 & 2.327 & 0.30 \\
\hline 5 & 3950.331 & 3.416667 & 15461.56 & 1.593 & 0.45 \\
\hline 6 & 4076.325 & 3.05 & 33952.75 & 1.876 & 0.17 \\
\hline 7 & 7266.136 & 4.888889 & 26744.32 & 1.516 & 0.33 \\
\hline 8 & 3314.071 & 2.857143 & 25386.21 & 1.833 & 0.18 \\
\hline 9 & 9914.812 & 5.8125 & 22356.58 & 1.387 & 0.28 \\
\hline 10 & 7252.298 & 4.0952 & 22983.4 & 1.549 & 0.31 \\
\hline
\end{tabular}

\subsection{Dimensionless relation for frosting on air- cooler tubes}

Assuming that the evaporator tube and the fin have the same moisture content, the dimensionless relation of frost layer frosting on the evaporator tube is obtained by a similar method. Frost changes the geometric structure of the air passages and makes the wind speed value related to the Reynolds number have a significant change. Therefore, it is necessary to combine the inlet wind speed with the thickness of the frost layer to calculate the average speed in front of the evaporation tube. Similarly, V/A in the Fourier number is replaced by the thickness. Put the data into the formula, and the values of each dimensionless number under different working conditions are shown in Table 3. The dimensionless equation of frost layer growth is:

$$
M_{\text {tube }}{ }^{*}=m F O_{L}^{a} \cdot\left(T^{*}\right)^{b} \cdot \operatorname{Re}_{L, f i n}^{c} \cdot \omega^{d}
$$

Then, we can choose the appropriate values of $\mathrm{m}$, $\mathrm{a}, \mathrm{b}, \mathrm{c}$ and $\mathrm{d}$, and make the selected points and points on the curve as close to the curve as possible. Then, the fitting curves of the five groups of data are as follows:

$$
\begin{aligned}
& M_{\text {tube }}{ }^{*}= \\
& 1.523 \times 10^{-2} F_{O_{L}^{-0.3658}} \cdot\left(T^{*}\right)^{1.643} \cdot \mathrm{Re}_{L, \text { fin }}^{0.3452} \cdot \omega^{0.5096}
\end{aligned}
$$


Table 3. Parameter values under different operating conditions.

\begin{tabular}{|c|c|c|c|c|c|}
\hline Item & $F O_{L}$ & $\mathrm{~T}^{*}$ & $\mathrm{Re}_{L, \text { fin }}$ & Moisture content $\omega(\mathrm{g} / \mathrm{kg})$ & $M^{*}$ \\
\hline 1 & 2137.88 & 0.4625 & 2458.72 & 2.426 & 0.056 \\
\hline 2 & 5348.52 & 2.352941 & 1727.2 & 1.655 & 0.094 \\
\hline 3 & 2216.45 & 0.618182 & 2377.44 & 2.506 & 0.055 \\
\hline 4 & 2854.87 & 0.727273 & 2174.24 & 2.327 & 0.049 \\
\hline 5 & 3451.26 & 2.157895 & 1503.68 & 1.593 & 0.117 \\
\hline 6 & 26117.94 & 1.487805 & 3302 & 1.876 & 0.016 \\
\hline 7 & 24321.48 & 3.034483 & 2600.96 & 1.516 & 0.044 \\
\hline 8 & 15217.67 & 1.666667 & 2468.88 & 1.833 & 0.021 \\
\hline 9 & 18881.77 & 3.321429 & 2174.24 & 1.387 & 0.050 \\
\hline 10 & 26820.63 & 2.965517 & 2235.2 & 1.549 & 0.039 \\
\hline
\end{tabular}

\section{Conclusions}

(1) After 2 hours, the frost layer growth of evaporator tubes and fins at the measuring point 5 showed a linear growth.

(2) Under the high humidity condition, the thickness of the frost layer on the evaporator tube increases with the increase of the plenum chamber coefficient, and the frost layer thickness on the fins first increases and then decreases with the increase of the plenum chamber coefficient.

(3) The fitting curves of the fin are respectively:

$$
\begin{aligned}
& M_{\text {fin }}{ }^{*}= \\
& 1.333 \times 10^{-10} \mathrm{Fo}_{L}^{0.3764} \cdot\left(T^{*}\right)^{-0.1011} \cdot \operatorname{Re}_{L, f i}^{2.059} \cdot \omega^{-1.968}
\end{aligned}
$$

or

$$
\begin{aligned}
& M_{\text {fin }}^{*}= \\
& 1.82 \times 10^{-7} \mathrm{FO}_{L}^{-2.345} \cdot\left(T^{*}\right)^{-10.1768} \cdot \mathrm{Re}_{L, \text { fin }}^{6.6566} \cdot \omega^{-39.5362}
\end{aligned}
$$

(4) The fitting curve of the evaporation tube is:

$$
\begin{aligned}
& M_{\text {tube }}{ }^{*}= \\
& 1.523 \times 10^{-2} \mathrm{Fo}_{L}^{-0.3658} \cdot\left(T^{*}\right)^{1.643} \cdot \mathrm{Re}_{L, \text { fin }}^{0.3452} \cdot \omega^{0.5096}
\end{aligned}
$$

\section{Acknowledgments}

This work is funded by Tianjin Committee of Agriculture and Rural Affairs (No. 201901290).

\section{Nomenclature}

$\begin{array}{cc}C & \text { The specific heat capacity }[\mathrm{J} /(\mathrm{kg} \cdot \mathrm{K})] \\ F_{L} & \text { Fourier number } \\ L_{f i n} & \text { The length of fin }[\mathrm{m}] \\ M^{*} & \text { Dimensionless mass } \\ M_{f r} & \text { Frosting quality }[\mathrm{kg}] \\ \mathrm{Re}_{L, f i n} & \text { Reynolds number } \\ T^{*} & \text { Dimensionless temperature } \\ T_{a} & \text { Wet air temperature }\left[{ }^{\circ} \mathrm{C}\right] \\ T_{t p} & \text { The triple point temperature }\left[{ }^{\circ} \mathrm{C}\right] \\ T_{w} & \text { The cold surface temperature }\left[{ }^{\circ} \mathrm{C}\right] \\ \text { Greek symbols } & \text { Thermal conductivity }[\mathrm{W} /(\mathrm{m} \cdot \mathrm{K})] \\ \lambda & \text { Viscosity }[\mathrm{Pa} \cdot \mathrm{s}]\end{array}$

$$
\begin{array}{cc}
\Phi & \text { Plenum chamber coefficient } \\
w_{a} & \text { Moisture content }[\mathrm{g} / \mathrm{kg}] \\
\xi_{f i n} & \text { Fin thickness }[\mathrm{mm}] \\
\kappa_{f i n} & \text { Thermal conductivity }[\mathrm{W} /(\mathrm{m} \cdot \mathrm{K})] \\
\kappa_{f i n, r} & \text { Reference value of the thermal } \\
\xi_{f i n}^{*} \cdot \kappa_{f i n}^{*} & \begin{array}{c}
\text { The productivity }[\mathrm{W} /(\mathrm{m} \cdot \mathrm{K})] \\
\text { thickness and thermal conductivity }
\end{array}
\end{array}
$$

\section{References}

1. Shi-qiong $\mathrm{Xu}, \mathrm{Lie} \mathrm{Xu}$, Dong-quan Deng. Experimental investigation on the performance of air cooler under frosting conditions[J]. Applied thermal engineering: Design, processes, equipment, economics,2003,23(7):905-912.

2. Caglayan, Akin, Konukman, Alp Er S., Bayrak, Ergin. Experimental investigation of the effect of air velocity on a unit cooler under frosting condition: a case study $[\mathrm{J}]$. Heat and mass transfer,2017,53(10):3119-3128.

3. Zhongliang Liu,Xinhua Zhang,Sheng Meng, et al.An experimental study on minimizing frost deposition on a cold surface under natural convection conditions by use of a novel antifrosting paint. Part I. Anti-frosting performance and comparison with the uncoated metallic surface[J]. International Journal of Refrigeration,2006,29(2):229-236.

4. Dang, Chaobin,Song, Mengjie.Review on the measurement and calculation of frost characteristics[J].International Journal of Heat and Mass Transfer,2018,124:586-614.

5. Mohammad Rafati Nasr,Melanie Fauchoux,Robert W. Besant, et al.A review of frosting in air-to-air energy exchangers[J].Renewable \& sustainable energy reviews,2014,30(Feb.):538-554.

6. Wu, Xiaomin,Chu, Fuqiang, Wang, Lingli.Meltwater Evolution during Defrosting on Superhydrophobic Surfaces[J].ACS applied materials \& interfaces,2018,10(1):1415-1421.

7. Lee YB.,Ro ST..Frost formation on a vertical plate in simultaneously developing flow $[\mathrm{J}]$.Experimental Thermal and Fluid Science: International Journal of Experimental Heat 
Transfer, Thermodynamics, and Fluid

Mechanics,2002,26(8):939-945.

8. Experimental study on the frosting characteristics of round tube in confined circular flow path at low temperature $[\mathrm{J}]$. Applied thermal engineering:

Design, processes, equipment, economics, 2020,171.

9. Chin-Hsiang Cheng,Keng-Hsien Wu.Observations of Early-Stage Frost Formation on a Cold Plate in Atmospheric Air Flow[J].Journal of heat transfer: Transactions of the ASME,2003,125(1):95-102.

10. Lee, J., Domanski, P. A..Impact of air and refrigerant maldistributions on the performance of finned-tube evaporators with R-22 and R-407C. Final Report[R].

11. Yeun-Jong Wu,Jian-Yuan Lin,Wei-Mon Yan, et al.Performance of finned tube heat exchangers operating under frosting conditions[J].International Journal of Heat and Mass Transfer,2003,46(5):871-877.

12. Deniz Seker,Nilufer Egrican,Hakan Karatas.Frost formation on fin- and- tube heat exchangers. Part II-Experimental investigation of frost formation on fin- and- tube heat exchangers[J]. International Journal of Refrigeration,2004,27(4):375-377.

13. Z.L. Liu, Y.W. Dong, Y.X. Li, An experimental study of frost formation on cryogenic surfaces under natural convection conditions, Int. J. Heat Mass Transfer 97 (2016) 569-577.

14. Wu, Xiaomin,Chu, Fuqiang,Ma, Qiang, et al.Frost formation and frost meltwater drainage characteristics on aluminum surfaces with grooved structures $[\mathrm{J}]$.Applied thermal engineering: Design, processes, equipment, economics,2017,118:448454.

15. Liu, Zhongliang,Li, Yanxia,Dong, Yuwan.An experimental study of frost formation on cryogenic surfaces under natural convection conditions[J].International Journal of Heat and Mass Transfer,2016,97:569-577.

16. An experimental study on the air side heat transfer performance of the perforated fin-tube heat exchangers under the frosting conditions[J]. Applied thermal engineering: Design, processes, equipment, economics,2020,166. DOI: 10.1016/j.applthermaleng.2019.114634.

17. Chiuan-Che Shiu,Chin-Hsiang Cheng. Frost formation and frost crystal growth on a cold plate in atmospheric air flow [J]. International Journal of Heat and Mass Transfer,2002,45(21):4289-4303.

18. Kim, Donghee,Kim, Chiwon,Lee, KwanSoo.Frosting model for predicting macroscopic and local frost behaviors on a cold plate[J].International Journal of Heat and Mass Transfer,2015,82:135-142.

19. Wu, Xiaomin,Ma, Qiang,Chu, Fuqiang, et al.Phase change mass transfer model for frost growth and densification[J].International Journal of Heat and Mass Transfer,2016,96:11-19.
20. Cardoso, Rodrigo P.,Hermes, Christian J. L.,Negrelli, Silvia.A finite-volume diffusionlimited aggregation model for predicting the effective thermal conductivity of frost[J].International Journal of Heat and Mass Transfer,2016,101:1263-1272.

21. Breque, Florent,Nemer, Maroun.Frosting modeling on a cold flat plate: Comparison of the different assumptions and impacts on frost growth predictions [J].International Journal of Refrigeration,2016,69:340-360.

22. Benitez, Teresa,Sherif, S. A...Modeling spatial and temporal frost formation with distributed properties on a flat plate using the orthogonal collocation method[J].International Journal of Refrigeration,2017,76:193-205.

23. Sommers, Andrew D., Napora, Andrew C., Truster, Nicholas L., et al.A semi-empirical correlation for predicting the frost density on hydrophilic and hydrophobic substrates[J].International Journal of Refrigeration,2017,74:313-323.

24. Zendehboudi, Alireza,Wang, Baolong,Li, Xianting.Application of smart models for prediction of the frost layer thickness on vertical cryogenic surfaces under natural convection $[\mathrm{J}]$.Applied thermal engineering: Design, processes, equipment, economics,2017,115:1128-1136.

25. Ren, Lemei,Jiao, Wenling, Tian, Xinghao, et al.Effect of frost layer on heat transfer of cryogenic fluid in a finned tube[J].Cryogenics, 2020,109. DOI: 10.1016/j.cryogenics.2020.103115.

26. Dong-Keun Yang,Jung-Soo Kim,Kwan-Soo Lee.Dimensionless correlations of frost properties on a cold cylinder surface[J].International Journal of Heat and Mass Transfer,2008,51(15/16):39463952.

27. Mooyeon Lee,Yongchan Kim,Won Jae Yoon, et al.Frost growth characteristics of spirally-coiled circular fin-tube heat exchangers under frosting conditions[J].International Journal of Heat and Mass Transfer,2013,64:1-9.

28. Groll EA, Braun JE, Bach CK (2011) Optimizing refrigerant distribution in Evaporators. Final project report prepared for California Energy Commission, Purdue University, USA.

29. Dietenberger M A. Generalized correlation of the water forst thermal conductivity. International Journal of Heat and Mass Transfer, 1983, 26(4):607-619.

30. Y.X. Tao, R.W.Besat, K.S.Rezkallah,A mathematical model for prediction the densification and growth of frost on a flat plate[J].International Journal of heat and mass transfer, 1993,36(2):353-363. 